\title{
Relationships between yield, rotation length, and abundance of Olpidium brassicae and Pyrenochaeta sp. in the rhizosphere of oilseed rape
}

by Bennett, A.J., Hilton, S., Chandler, D., Mills, P. and Bending, G.D.

Copyright, publisher and additional Information: This is the author accepted manuscript. The final published version (version of record) is available online via Elsevier.

This version is made available under the CC-BY-ND-NC licence:

https://creativecommons.org/licenses/by-nc-nd/4.0/legalcode

Please refer to any applicable terms of use of the publisher

DOI: https://doi.org/10.1016/j.apsoil.2019.103433

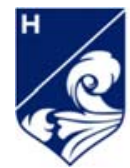

Harper Adams University 
1 Relationships between yield, rotation length, and abundance of Olpidium brassicae and

2 Pyrenochaeta sp. in the rhizosphere of oilseed rape

3 Amanda J. Bennett ${ }^{\ddagger * a b}$, Sally Hilton ${ }^{\ddagger a}$, David Chandler ${ }^{\mathrm{a}}$, Peter Mills ${ }^{\text {ac }}$ and Gary D. Bending ${ }^{\mathrm{a}}$

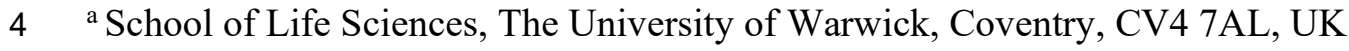

5 b Current address: Agriculture and Horticulture Development Board, Stoneleigh Park,

$6 \quad$ Kenilworth, CV8 2TL, UK

$7 \quad{ }^{\mathrm{c}}$ Current address: Harper Adams University, Newport, Shropshire, TF10 8NB, UK

$8 \quad{ }^{\ddagger}$ Sally Hilton and Amanda Bennett are joint first authors

$9 \quad{ }^{*}$ Corresponding author: email: amanda.bennett@ahdb.org.uk; Tel: 02476478951

\section{Abstract}

12 Oilseed rape yields in the UK have been found to decline with more frequent cropping in a 13 rotation. Previously, two soil-borne organisms (Olpidium brassicae (Chytridiomycota) and 14 Pyrenochaeta sp. (Ascomycota)) were identified as having high relative abundance in rhizosphere fungal communities associated with oilseed rape crops where yield decline had been recorded. In order to better understand these organisms' association with the oilseed rape

17 crop, the current study was designed to investigate the fungal rhizosphere microbiome of 18 oilseed rape grown in a wide range of rotational frequencies. Samples collected from a long19 term rotation trial site at three time points through the growing season were used to determine 20 fungal community composition, and quantification of $O$. brassicae and Pyrenochatea sp. 21 Analyses showed the combined root and rhizosphere fungal communities were similar across 22 all oilseed rape rotations, largely due to the high relative abundance of $O$. brassicae, 23 irrespective of cropping frequency. Olpidium brassicae abundance peaked in March (mid24 season) in all rotations, before declining in abundance by June (pre-harvest). In contrast, 25 Pyrenochaeta sp. increased in abundance throughout the season, with significantly higher 
26 levels reached in June than earlier in the season. Pyrenochaeta sp. had a greater relative

27 abundance in the rhizosphere fungal community of alternate oilseed rape (grown one year in

28 two) than in rotations with longer gaps between oilseed rape crops. This study concludes that

29 O. brassicae cannot be solely associated with yield decline of OSR observed in short rotation

30 cropping due to its prevalence in the extended rotations examined (up to 6-year gap).

\section{Key words}

33 Oilseed rape, T-RFLP, qPCR, Olpidium brassicae, Pyrenochaeta sp., rotation, yield

\section{Introduction}

Monocultures and short crop rotations, where the same crop is grown once every three years or less, have been common in global agriculture in recent times due to a range of technical, economic and social drivers. However, short rotation cropping is also associated with yield declines in many crops, including oilseed rape (OSR; Brassica napus) (Bennett et al., 2012). Oilseed rape is a globally significant crop, grown for biofuel, production of animal feed and oil for human consumption (Weightman et al., 2010; Carré and Pouzet, 2014). In 2018/2019 $70.9 \mathrm{M}$ metric tons of rapeseed were produced, second only to soybean in the major oilseeds market (USDA, 2019). However, frequent cropping of OSR in short rotations with wheat

44 (Triticum aestivum) has been associated with reduced yields of up to 25\% in the UK (Stobart 45 and Bingham, 2013).

47 The cause of OSR yield decline is not straightforward and may arise in part from changes in soil biology, particularly selection of deleterious microbiomes with repeated cropping (Bennett et al., 2012). Hilton et al. (2013) demonstrated that increased cropping frequency of OSR, as

50 part of a rotation with wheat, resulted in a shift in fungal communities associated with the 
rhizosphere and roots. In particular, they found that Olpidium brassicae and Pyrenochaeta sp. increased in abundance in the rhizosphere of OSR grown for four consecutive years, compared to when grown for the first time (Hilton et al., 2013). Olpidium brassicae is an obligate plant parasite of brassicas, including OSR (Lay et al., 2018a, 2018b). It survives in soil for many years in the form of resting spores, which germinate in the presence of a host plant to produce infectious zoospores that infect the roots (Singh and Pavgi, 1977).

Hilton et al. (2013) determined that the Pyrenochaeta sp. isolated from OSR was found to have a high similarity to P. lycopersici, the causal organism of tomato corky rot. Pyrenochaeta lycopersici produces microsclerotia that can remain viable in the soil for long periods and, under favourable conditions, hyphae germinate and infect the epidermal cells of host roots (Aragona et al., 2014). Visible symptoms of tomato corky root are brown lesions in the roots and swelling of root epidermis with subsequent cracking into a corky texture (Varela et al., 2009). As similar symptoms were seen on brassica species inoculated with Pyrenochaeta sp. isolated from OSR (Hilton et al., 2013), the infection mechanism of this species may be similar.

The potential of $O$. brassicae and Pyrenochaeta sp. to impact negatively on rooting and plant productivity was demonstrated in glasshouse bioassays using the model crop species Brassica oleracea (Hilton et al., 2013) and, taken together, the evidence suggested that $O$. brassicae and Pyrenochaeta sp. are deleterious organisms associated with reduced yield of OSR grown in short rotations.

OSR is susceptible to a range of plant pathogens including Rhizoctonia solani, Verticillium 74 longisporum, Plasmodiophora brassicae and Sclerotinia sclerotiorum (AHDB, 2014), which interact with the crop at different stages of plant growth during the season due to their differing 
76 life-cycles and trophic states. For example, $R$. solani typically infects the germinating seed and

77 young seedlings of OSR to cause pre- and post-emergence damping-off, thereby impacting on crop establishment (Verma, 1996; Sturrock et al., 2015). In contrast, V. longisporum produces soil-borne resting spores (microsclerotia), which germinate to produce hyphae that penetrate the root, allowing the pathogen to colonise vascular tissue (xylem). Symptoms are seen later in the season as the pathogen causes premature ripening and yield losses up to 50\% (Gladders, 82 2009).

However, little is known about the seasonal dynamics of O. brassicae and Pyrenochaeta sp., or about the impact of rotation gaps on the root and rhizosphere fungal community compositions of OSR. This is important because extending the rotation gap between host crops can be used by farmers in an attempt to manage soil-borne plant diseases, alongside other cultural practices such as sanitation, changing tillage operations, altering sowing date or applying soil amendments (Katan, 2017; Burnett et al., 2013).

Here we used a long-term field trial to investigate links between OSR cropping frequency, crop yield and the rhizosphere abundance of O. brassicae and Pyrenocheata sp. Firstly, we used Terminal Restriction Fragment Length Polymorphism (T-RFLP) of fungal internal transcribed spacer regions (ITS), which gives relative species abundance, to investigate the seasonal population dynamics of the rhizosphere fungal communities associated with OSR grown under a wide range of cropping frequencies. Secondly, we used quantitative PCR to determine how cropping frequency affected the absolute abundance of $O$. brassicae and Pyrenochaeta sp. in the rhizosphere of OSR at three times in the growing season, and the relationships between abundance of these pathogens and crop yield. 


\section{Materials and methods}

The study made use of a long-term field trial in Morley, East Anglia, UK, in which OSR and wheat were grown according to different rotations in randomised plots (Table 1) (Hilton et al., 2013; Stobart and Bingham, 2013; Hilton et al., 2018). The trial was on a sandy-loam soil and was managed according to conventional practices (Hilton et al., 2013). Plants were sampled from different rotation frequencies of OSR during the eighth year following establishment of the trial, as indicated in Table 1. Samples were taken as previously described (Hilton et al., 2013; Hilton et al., 2018), from four replicate plots for each of the following OSR rotations: 6year gap, 4-year gap, 3-year gap, 2-year gap, 1-year gap (ie alternate years of OSR) and OSR grown continuously for 8 years. Six plants were dug up and pooled to comprise one sample from each replicate plot. Field sampling took place at three points in the growing season: January (early growth stage; leaf development), March (mid-season; stem extension) and June (pre-harvest, seed development).

OSR harvest yield data were collected and analysed as part of a related study using the same plots at the long-term experimental site, with a central sub-plot $(2 \mathrm{~m} \times 24 \mathrm{~m})$ of each plot harvested using a plot combine (Stobart and Bingham, 2013). Yields ( $t /$ ha) are quoted as 91\% dry matter (Stobart and Bingham, 2013).

For samples collected in January, March and June, processing took place in the laboratory: roots were shaken free of loose soil, and fine roots were cut into approximately $5 \mathrm{~mm}$ sections. Fine roots plus closely adhering soil were designated as rhizosphere samples, and sub-samples $(0.5 \mathrm{~g})$ were frozen for molecular analyses, all of which were conducted as described in Hilton et al. (2013). DNA extraction, T-RFLP and quantitative PCR protocols were conducted as previously described (Hilton et al., 2013). Briefly, DNA was extracted from rhizosphere 
samples and amplified with fungal internal transcribed spacer (ITS) region primers (ITSf1 and ITS4r). Terminal restriction fragments were generated with the restriction enzyme HhaI, with TRF of 284 and 98 bp corresponding to O. brassicae and Pyrenochaeta sp. respectively, as confirmed in Hilton et al. (2013). T-RFLP community profiles were expressed in relative abundance (based on TRF peak heights). Supplemental Table S1 reports the mean number of TRFs for each treatment, out of 144 different TRFs recorded in total.

Abundance of O. brassicae and Pyrenochaeta sp. was determined using quantitative PCR using the species specific primers to the ITS region of the rRNA gene and the conditions reported in Hilton et al. (2013): ObF (5'-TCT CCT CGT TGG GAA GAC TTG T-3') and ObR (5'-GAG CTT GAA TTT TTA AGT TCG TCG TT-3'); and PyF (5'-CCG CCG GTT GGA CAC TAT AA-3') and PyR (5'-TCG ATG CCA GAA CCA AGA GAT-3'). The quantities of DNA obtained were converted to copy numbers of rRNA gene / $\mu$ g total extracted DNA.

Statistical analyses were performed using R version 3.5.1 (R Core Team, 2016). Differences in population structure were tested by analysis of similarity (ANOSIM) with 999 permutations and non-metric multidimensional scaling (NMDS) using Bray-Curtis dissimilarities within the vegan package (Clarke, 1993; Oksanen et al., 2013). Quantitative PCR data were $\log _{10}$ transformed before correlation analysis with yield data and ANOVA, which was used to compare the abundance of $O$. brassicae and Pyrenochaeta sp. across rotations and sampling times.

\section{Results}

ANOSIM analysis showed there was no significant difference in rhizosphere fungal community composition with respect to cropping frequency of OSR ( $\mathrm{p}=0.798 \mathrm{R}=-0.017)$. 
However, there was a significant difference in fungal community composition between the three sample times (January, March, June) $(\mathrm{P}<0.001, \mathrm{R}=0.502)$, and the NMDS plot shows grouping by sampling time (Figure 1).

Olpidium brassicae increased significantly in copy number from January to March $(P<0.001)$, followed by a subsequent significant decline in June $(P<0.001)$, i.e. a mid-season peak occurred (Figure 2a). In contrast, Pyrenochaeta sp. increased in copy number over the season, with significantly higher levels being found pre-harvest in June compared to January $(P<0.001)$ or $\operatorname{March}(P<0.001)$ (Figure 2b).

Quantitative PCR showed no significant differences in O. brassicae copy number with different OSR rotation gaps at any time point (Figure S1). In contrast, Pyrenochaeta sp. had a significantly higher copy number in the continuous and alternate OSR rotation in January compared to the longer rotation gaps $(P<0.01$; Figure $2 \mathrm{c})$.

Linear regression confirmed a significant negative relationship between Pyrenochaeta sp. copy number and yield in January $\left(\mathrm{F}(1,22)=16.2, P<0.001, \mathrm{R}^{2}=0.424\right)$ and in March $(\mathrm{F}(1,22)=$ 7.1, $P=0.014, \mathrm{R}^{2}=0.243$ ) but not in June (Figure 3). There was no relationship between $O$. brassicae copy number and yield. Yield data from the sampled year of the field site (Stobart and Bingham, 2013) is shown in Figure 4. Yields in alternate and continuously cropped OSR were reduced by between $27 \%$ and $34 \%$ relative to rotations with between 3 and 6 year gaps.

\section{Discussion}

Previous studies have shown that more frequent cropping of OSR impacts negatively on yield, compared to longer rotation gaps and that $O$. brassicae and Pyrenochaeta sp. are implicated as 
putative pathogens that may be involved in yield reductions (Stobart and Bingham, 2013; Hilton et al., 2013). The results from this study indicate that the abundance of $O$. brassicae was not significantly different across a range of cropping frequencies of OSR and that extending the rotation gap did not reduce relative abundance of this organism associated with the crop. As a yield reduction was still observed in OSR crops grown in shorter rotations in this study, we conclude that $O$. brassicae cannot be solely associated with yield decline of OSR. Olpidium brassicae spores are known to survive in soil for many years and these results suggest that once OSR has been previously grown, then for at least a 6-year rotation gap $O$. brassicae is able to infect OSR plants to a similar extent.

This study, in contrast to Hilton et al., 2013, did not include plots where OSR was grown for the first time (virgin land), which would have been likely to have shown lower levels of $O$. brassicae. Lay et al. (2018a) similarly found that O. brassicae dominated the fungal core microbiome of oilseed rape (canola) in Canada, but that it was not significantly correlated with yield. It may, however, play a role in allowing other soil-borne organisms entry to the root through initial infection sites (wounds), or through weakening the root systems more generally due to its biotrophic state, resulting in a less tolerant crop overall. Although not addressed in this research, another consideration is the increased aggressiveness or virulence of strains with continuous cropping (El-Nashaar and Stack, 1989).

Pyrenochaeta sp. was found in greater abundance in the rhizosphere early in the season (January) in rotations where OSR was grown in close succession (continuous or alternate crops). Bennett et al. (2014) showed that Pyrenochaeta sp. survives in mature root residues of OSR, so it is likely that there is carry-over of inoculum from residues into an OSR crop that follows in short succession. In this case, extended rotations would be of benefit in reducing 
inoculum as crop debris breaks down over time. Although the abundance of Pyrenochaeta sp. was lower than that of $O$. brassicae, there was a correlation between higher absolute abundance (qPCR) found early in the season and lower yield at harvest. Accepting that correlation is not evidence of causation, it would seem possible that in situations where there is a high inoculum potential during the active stage of crop growth and seed set, this fungus may have potential to impact on OSR productivity. The mechanism for this is not confirmed from field studies with OSR, but Hilton et al. (2013) demonstrated in glasshouse studies that Pyrenochaeta sp. resulted in the development of root lesions in young plants of Brassica oleracea and, in high doses, delayed flowering and reduced seed weight, quality and quantity per pod. Additional research is required to better understand how Pyrenochaeta sp. interacts with OSR crops.

In the field, both $O$. brassicae and Pyrenochaeta sp. show strong seasonal differences in abundance: O. brassicae peaked in March, when the crop was actively growing, whereas Pyrenochaeta sp. peaked in June when the crop was senescing. Although seasonal differences are likely due to a combination of plant age, climatic and edaphic factors, the temporal differences in the abundance of these two organisms within the OSR microbiome associated with plant age is likely to be due to their trophic states. As an obligate parasite (biotroph), $O$. brassicae requires living plant cells for nutrients (Singh and Pavgi, 1977; Raaijmakers, 2009). Higher abundance of Pyrenochaeta sp. in rhizosphere samples obtained pre-harvest in this study corroborate the findings of Bennett et al. (2014), where Pyrenochaeta sp. was found to survive in high numbers on mature (field-derived) OSR root residues collected immediately after harvest.

The different times of peak abundance of the two organisms investigated in this study show that seasonal dynamics of rhizosphere microorganisms should be taken into account in trying 
to better understand rhizosphere ecology and its impact on crop productivity. In assessing only one point in the growing season, there is a risk of not capturing fluctuations in population growth of key organisms. Factors involved in temporal dynamics of soil-borne pathogen epidemics include the starting inoculum potential, how quickly they can grow and reproduce, and whether they are monocyclic or polycyclic (Raaijmakers et al., 2009). Seasonal sampling time and plant development age has also been shown to influence fungal, bacterial and nematode rhizosphere communities in winter wheat and OSR (Hilton et al., 2018), and bacterial communities in the rhizosphere of crops including OSR, strawberry and potato (Smalla et al., 2001; Farina et al., 2012).

235

Other glasshouse bioassays carried out as part of this wider research indicated Rhizoctonia and a range of techniques should be utilised.

247

Acknowledgments: The authors thank the Department for Environment Food and Rural 250

solani to be a virulent pathogen of OSR (data not shown), although this pathogen was not evident from T-RFLP community analysis using the primers described throughout the current work (Hilton et al., 2013; Bennett et al., 2014; Hilton et al., 2018). However, other research using qPCR primers specific to Rhizoctonia solani has also shown this pathogen to be widespread in commercial OSR crops in the UK (McCormack, 2018). Other molecular techniques such as high throughput sequencing are now used routinely to provide greater resolution of microbial communities, although these should be complemented with qPCR if data on absolute abundance of a pathogen are required. In order to better understand the rhizosphere microbiome, samples should be taken repeatedly throughout the growing season

Affairs (Defra) for funding this work as part of project IF0128. We also thank Ron Stobart (formerly at NIAB TAG) for providing yield data, and TAG Morley for allowing us to collect 
soil from the rotational field trial for use in this work. The field trial was funded by AHDB Cereals \& Oilseeds (previously HGCA), which is a division of the Agriculture and Horticulture Development Board.

\section{References}

AHDB, 2014. Oilseed rape guide.

Aragona, M., Minio, A., Ferrarini, A., Valente, M.T., Bagnaresi, P., Orrù, L., Tononi, P., Zamperin, G., Infantino, A., Valè, G., Cattivelli, L., Delledonne, M. 2014. De novo genome assembly of the soil-borne fungus and tomato pathogen Pyrenochaeta lycopersici. BMC Genomics. 15: 313.

Bennett, A.J., Bending, G.D., Chandler, D., Hilton, S., Mills, P. 2012. Meeting the demand for crop production: the challenge of yield decline in crops grown in short rotations. Biol. Rev. 87, 52-71.

Bennett, A.J., Hilton, S., Bending, G.D., Chandler, D., Mills, P. 2014. Impact of fresh root material and mature crop residues of oilseed rape (Brassica napus) on microbial communities associated with subsequent oilseed rape. Biol. Fertil. Soils 50:1267-1279.

Burnett, F., Gladders, P., Smith, J.A., Theobald, C. 2013. Management of clubroot (Plasmodiophora brassicae) in winter oilseed rape. AHDB Cereals \& Oilseeds Project Report No. 487.

Carré, P., Pouzet, A. 2014. Rapeseed market, worldwide and in Europe. OCL 21(1) D102

Clarke, K.R. 1993. Nonparametric Multivariate Analyses of Changes in Community Structure. Aus. J. Ecol. 18:117-143.

El Nashaar, H.M., Stack, R.W. 1989. Effect of long-term continuous cropping of spring wheat on aggressiveness of Cochliobolus sativus. Can. J. Plant Sci. 69: 395-400. 
Gladders, P. 2009. Relevance of verticillium wilt (Verticillium longisporum) in winter oilseed rape in the UK. AHDB Cereals \& Oilseeds Research Review No. 72.

Farina, R., Beneduzi, A., Ambrosini, A., de Campos, S., Lisboa, B.B., Wendisch, V., Vargas, L.K., Passaglia, L.P. 2012. Diversity of plant growth-promoting rhizobacteria communities associated with stages of canola growth. Appl. Soil Ecol. 55:44-52.

Hilton, S., Bennett, A.J., Keane, G., Bending, G.D., Chandler, D., Stobart, R., Mills, P. 2013. Impact of shortened crop rotation of oilseed rape on soil and rhizosphere microbial diversity in relation to yield decline. PLoS ONE 8(4):e59859.

Hilton, S., Bennett, A.J., Chandler, D., Mills, P., Bending, G.D. 2018. Preceding crop and seasonal effects influence fungal, bacterial and nematode diversity in wheat and oilseed rape rhizosphere and soil. Appl. Soil Ecol. 126: 34-46.

Katan, J. 2017. Diseases caused by soilborne pathogens: Biology, management and challenges. J. Plant Path. 99 (2), 305-315.

Lay, C-Y., Bell, T.H., Hamel, C., Harker, K.N., Mohr, R., Greer, C.W., Yergeau, É., StArnaud, M. 2018a. Canola root-associated microbiomes in the Canadian Prairies. Front. Microbiol. 9:1188. doi: 10.3389/fmicb.2018.01188.

Lay, C-Y., Hamel, C., St-Arnaud, M. 2018b. Taxonomy and pathogenicity of Olpidium brassicae and its allied species. Fungal Biol. 122:837-846.

McCormack, A. 2018. Soil-borne pathogens of oilseed rape (Brassica napus): assessing their distribution and potential contribution to yield decline. AHDB Student report SR44.48pp.

Oksanen, J., Blanchet, F. G., Kindt, R., Legendre, P., Minchin, P. R., O’Hara, R. B., et al. (2013) Vegan: Community Ecology Package. R Package Version 2.0-10. Available at: http://cran.r-project.org/package=vegan 
R Core Team (2016) R: A Language and Environment for Statistical Computing. In: R Foundation for Statistical Computing, Vienna, Austria. (2016).

Raaijmakers, J.M., Paulitz, T.C., Steinberg, C., Alabouvette, C., Moënne-Loccoz, Y. 2009. The rhizosphere: a playground and battlefield for soilborne pathogens and beneficial microorganisms. Plant Soil 321:341-361.

Singh, S.L., Pavgi, M.S. 1977. Olpidium brassicae in cabbage roots. Mycopathol. 62:47-52.

Smalla, K., Wieland, G., Buchner, A., Zock, A., Parzy, J., Kaiser, S., Roskot, N., Heuer, H., Berg, G. 2001. Bulk and rhizosphere soil bacterial communities studied by Denaturing Gradient Gel Electrophoresis: Plant-dependent enrichment and seasonal shifts revealed. Appl. Environ. Micro. 67 (10): 4742-4751.

Stobart, R.M., Bingham, I.J. 2013. The impact of previous cropping on oilseed rape. AHDB Cereals \& Oilseeds Project Report PR519, pp 80. Agriculture and Horticulture Development Board.

Sturrock, C.J., Woodhall, J., Brown, M., Walker, C., Mooney, S.J., Ray, R.V. 2015 Effects of damping-off caused by Rhizoctonia solani anastomosis group 2-1 on roots of wheat and oilseed rape quantified using X-ray Computed Tomography and real-time PCR. Front. Plant Sci. 6:461.

USDA. 2019 Oilseeds: World markets and trade. Foreign Agricultural Service/USDA, Office of Global Analysis, April 2019.

Varela, A.R., Ramert, B., Martensson, A. 2009. Potential use of biocontrol agents for control of Pyrenochaeta lycopersici in tomato crops. Acta Agriculturae Scandinavica Section B-Soil and Plant Science 59: 379-384.

Verma, P. 1996. Biology and control of Rhizoctonia solani on rapeseed: a review. Phytoprotection, 77(3), 99-111. 
323 Weightman, R., Gladders, P., Berry, P. 2010 Oilseed rape. In: Halford, N.G., Karp. A. (eds) 
Figure 1: MDS plot of T-RFLP data indicating differences in rhizosphere fungal communities taken from oilseed rape grown at different cropping frequencies, at different sampling times throughout the season. MDS analyses were derived from a Bray-Curtis similarity matrix constructed with percentage peak height data of TRFs. Each point represents one plot (four replicate plots for each treatment).

Figure 2: Population dynamics using quantitative PCR of Olpidium brassicae and Pyrenochaeta sp. associated with oilseed rape grown in rotation with winter wheat. a) Quantification of O. brassicae over the growing season; b) Quantification of Pyrenochaeta sp. over the growing season c) Quantification of Pyrenochaeta sp. early season (January) in different rotational cropping frequencies. Bars represent means \pm SEM taken from four replicate field plots. Different letters indicate significant differences between groups $(p<0.05)$.

Figure 3: Negative correlation between oilseed rape yield and Pyrenochaeta sp. in the OSR rhizosphere in a) January, b) March an c) June. Pyrenochaeta sp. was quantified in rhizosphere samples taken from six different rotations of oilseed rape. Data are abundance data from qPCR and were $\log _{10}$ transformed before analysis.

Figure 4: Yield of oilseed rape grown in rotation with winter wheat, with six different rotation gaps between the oilseed rape crops, at a long-term experimental trial at Morley, Norfolk, UK. (from data presented in Stobart and Bingham, 2013). 
Supplemental Figure S1: Population dynamics of Olpidium brassicae and Pyrenochaeta sp. associated with oilseed rape grown in different frequencies in a rotation with winter wheat, and sampled at three times in the growing season. a) Quantification of O. brassicae; b) Relative abundance of $O$. brassicae in the rhizosphere fungal community as determined by T-RFLP; c) Quantification of Pyrenochaeta sp.; d) relative abundance of Pyrenochaeta sp. in the rhizosphere fungal community as determined by T-RFLP. Bars indicate standard error of the mean of samples taken from four replicate field plots. 


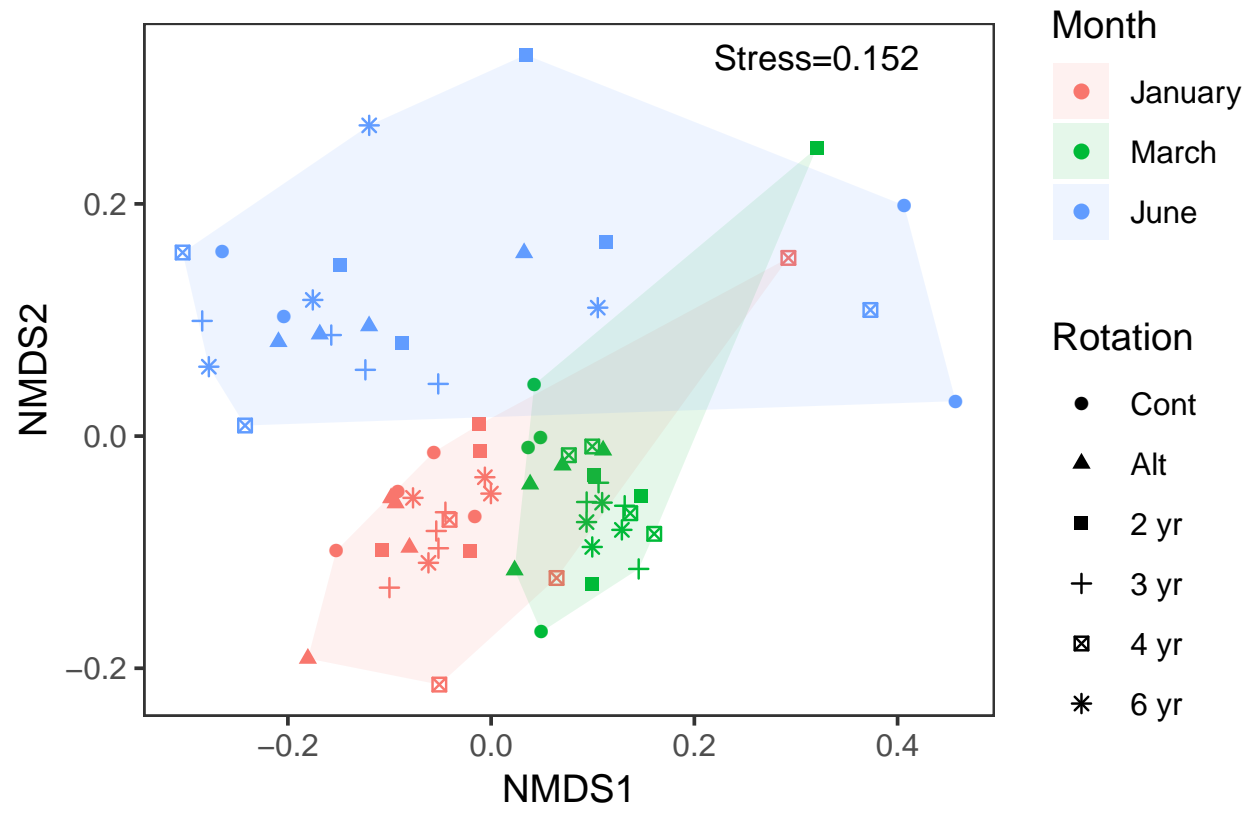




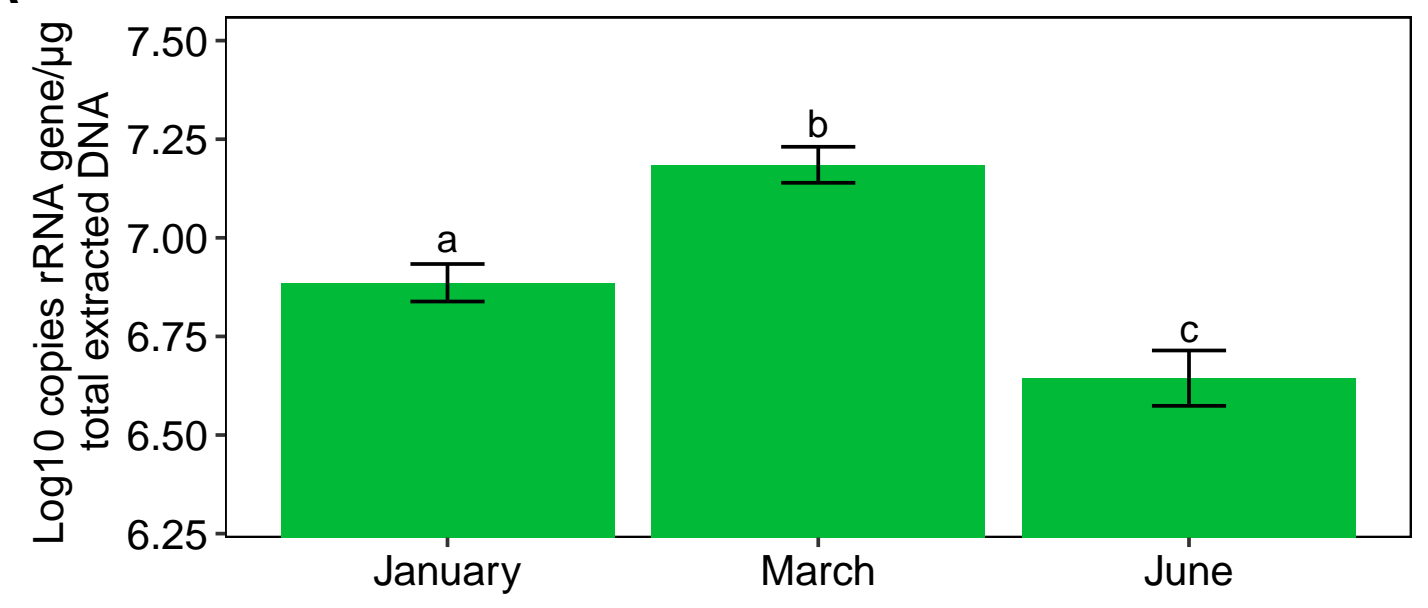

B
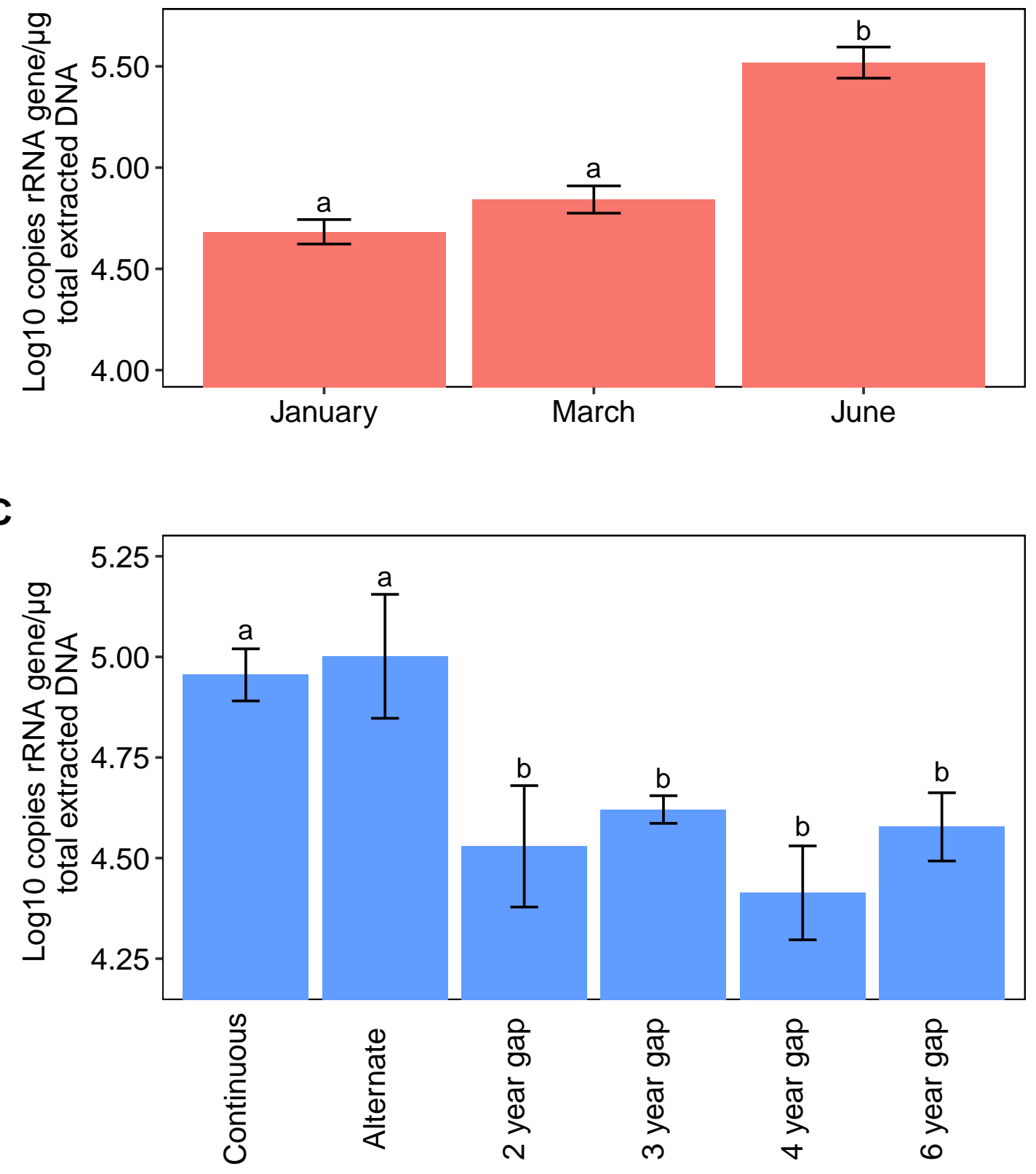
Fig.4

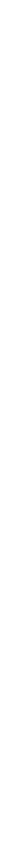


Fig.S1
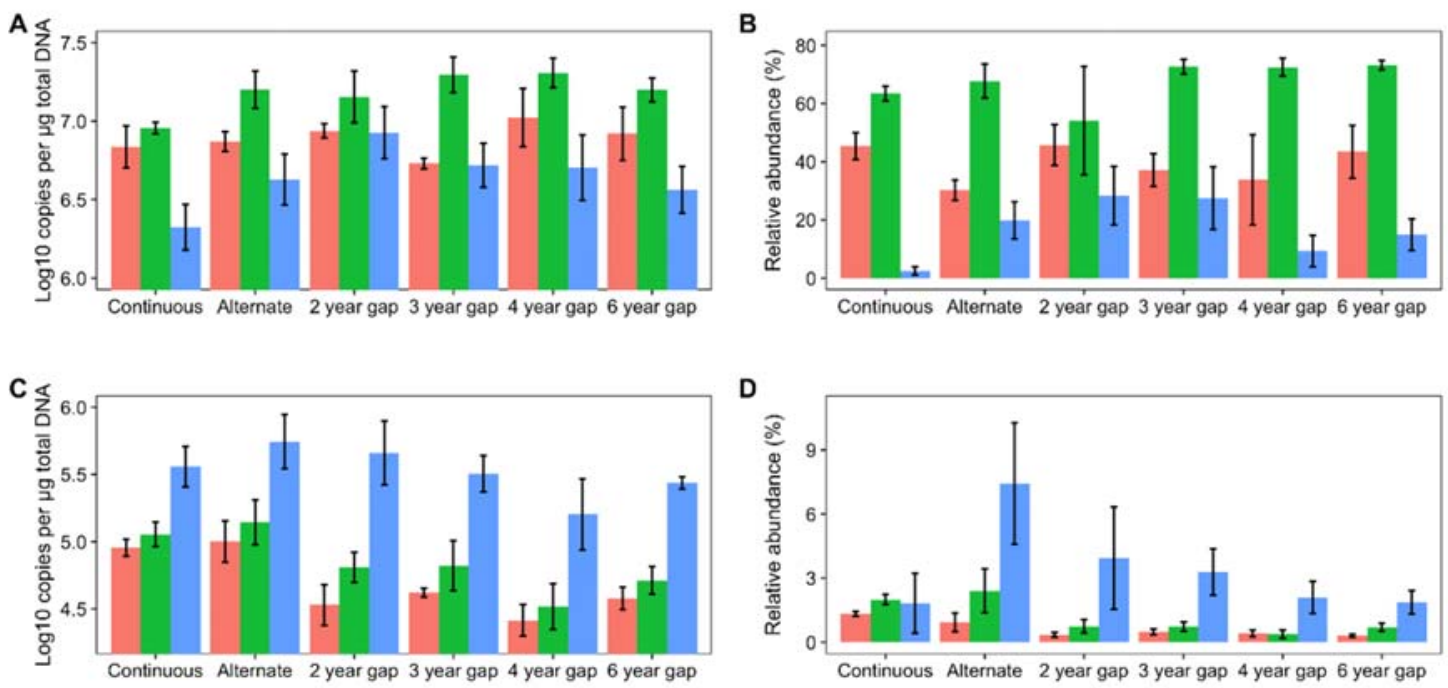

Month

- January

March

June 
Table 1: Cropping history of rotations sampled at long-term oilseed rape rotation trial at Morley, East Anglia, UK ( $\mathrm{O}=$ oilseed rape; $\mathrm{W}=$ winter wheat)

\begin{tabular}{lcccccccc} 
Rotation of & \multicolumn{8}{c}{ Year of trial } \\
\cline { 2 - 10 } oilseed rape & $\mathbf{1}$ & $\mathbf{2}$ & $\mathbf{3}$ & $\mathbf{4 \dagger}$ & $\mathbf{5}$ & $\mathbf{6}$ & $\mathbf{7}$ & $\mathbf{8} \ddagger$ \\
\hline Continuous & O & O & O & O & O & O & O & O \\
Alternate & W & O & W & O & W & O & W & O \\
2 year gap & W & O & W & W & O & W & W & O \\
3 year gap & W & W & W & O & W & W & W & O \\
4 year gap & W & W & O & W & W & W & W & O \\
6 year gap & O & W & W & W & W & W & W & O \\
\hline
\end{tabular}

† Oilseed rape sampled in year 4; described in Hilton et al. 2013

$\ddagger$ Oilseed rape sampled in current study 
Supplementary Table S1: Number of Terminal Restriction Fragments generated with the restriction enzyme Hhal, from rhizosphere samples collected from oilseed rape grown in a range of cropping frequencies (average of four replicates \pm standard deviation)

\begin{tabular}{|c|ccc|}
\hline & January & March & June \\
\hline Continuous & $137 \pm 2.9$ & $136 \pm 2.2$ & $133 \pm 11.6$ \\
Alternate & $137 \pm 0.5$ & $137 \pm 2.2$ & $135 \pm 9.6$ \\
2 year gap & $138 \pm 2.2$ & $134 \pm 8.7$ & $138 \pm 0.5$ \\
3 year gap & $137 \pm 5.4$ & $135 \pm 1.9$ & $140 \pm 1.0$ \\
4 year gap & $136 \pm 3.0$ & $135 \pm 1.9$ & $133 \pm 7.5$ \\
6 year gap & $139 \pm 0.5$ & $133 \pm 1.0$ & $137 \pm 1.0$ \\
\hline
\end{tabular}

